\title{
Influence of Altitudes and Air Humidity to the Minimum Gas Injection Rate in Air Underbalanced Drilling
}

\author{
Baojiang Sun*, Changsheng Xiang and Zhiyuan Wang
}

\author{
China University of Petroleum (Huadong), Qingdao 266555, China
}

\begin{abstract}
Three aspects, such as the optimization of calculation model for the minimum gas injection rate, the effect of elevation on the minimum gas injection rate, the effect of air humidity on the minimum gas injection rate, have been reviewed in this paper. Considering the influence of altitude and air humidity, correction factor for gas injection rate is calculated. The value of gas injection for altitude correction factor generally increases with the increase in altitude, especially when conducting air drilling in high altitude areas of western China the correction factor of Qinghai oilfield can be calculated as high as 1.5. When the air humidity increases, the gas injection humidity correction factor also increases; especially before raining in summer, the air humidity correction factor can be close to 1.1 , under the condition of relatively high air humidity and temperature. In the light of the calculation result and example analysis, it can be found that combining with this article's altitude and air humidity correction, the result of the amended minimum kinetic energy standard using Boyun Guo's correlation is the closest to the actual one, which can be used for the calculation of the minimum gas injection rate in industry practice while other methods have relatively larger errors.
\end{abstract}

Keywords: Air underbalanced drilling, the minimum gas injection rate, altitude, air humidity.

\section{INTRODUCTION}

Recently, gas underbalanced drilling technologies have widely been applied to counter the shortcomings such as loss formation, rigid formation with low drillability and water sensitive formation being easy to collapse [1-5]. The reasons are: the annulus pressure is lower in air drilling than that of conventional drilling, the chip hold down effect is slight and there exists no water in the drilling fluid. The calculation of the minimum gas injection rate is validated as one of the major technologies in gas underbalanced drilling. The algorithm is complicated since the density and viscosity of gas depend on temperature and pressure. Although a number of calculation models have been developed in the previous studies the calculation accuracy derivate among these models, which makes them suitable for their industry application is difficult. The minimum gas injection rate calculated by the current algorithm is considered as the rate under standard condition. W. C. Lyons and B.Y. Guo reported that the humidity and density of air terribly depend on the local elevation in high-altitudes areas [6], which signifies the influence of air humidity and the local elevation for the calculation of minimum gas injection rate in the highaltitude areas. In the light of numerous industry experiences and theory studies, this paper debates the improvement of minimum gas injection rate calculation theory concerning the selection of minimum gas injection calculation model, the influence of elevation and the gas humidity to the minimum gas injection rate.

* Address corresspondence College of Petroleum Engineering, China University of Petroleum(Huadong), B711 Laboratory Building of Engineering, No.66 Changjiang Road, E.,T. D. Zone, Qing Dao 266555, China; Tel: 053286983137; E-mail: Sunbj1128@upc.edu.cn

\section{THE SELECTION OF THE MINIMUM GAS IN- JECTION RATE MODEL}

The most common models generally used for calculation of minimum gas injection rate are: Minimum Kinetic Energy Method, Minimum Velocity Method and Key Point Method considering grain migration.

\subsection{The Minimum Kinetic Energy Standard Model}

The latest Minimum Kinetic Standard Model is the Angel Model [7] used to treat the mixture of solid and gas as homogeneous flow with uniform density and flow velocity. The required efficient minimum gas annulus flow velocity to carry solid grain under atmosphere condition in the well bore is presented as $v_{g 0}=15.24 \mathrm{~m} / \mathrm{s}$. However, when calculating the annulus friction loss, Angel model uses Weymouth Equation, which is used for the calculation of gas flow in horizontal smoothie pipe. Boyun Guo [8] reported the minimum gas injection rate calculated by this method as unsatisfactory. In order to overcome this flaw, Nikuradse friction coefficient [9] suitable for the calculation of friction loss in coarse well bore, is introduced into Angel Model to bring the calculation result closer to practice. William C. Lyons and Boyun Guo [6] proposed that minimum gas injection rate should be calculated CONSIDERING a minimum bottom-hole kinetic energy per unit volume of about $3.0 \mathrm{ft} \cdot \mathrm{lb} / \mathrm{ft}^{3}$.

\subsection{The Minimum Velocity Standard Model}

This method deals with the interaction between the solid grains and the fluid. When the solid grain is dropped into a low viscous fluid, the grain starts to accelerate due to the gravity. As the fluid friction increase, the grain starts to decelerate. It can mathematically be proved that the grain 
finally acquires uniform motion during a finite time period. This constant velocity of the uniform motion is called terminal velocity.

The grain terminal velocity is influenced by a plethora of factors such as grain size, grain shape, grain density, fluid density and viscosity, flow pattern and the interaction between grains and the wall of the container. Many mathematical models are proposed to describe the effect of these factors. Supposing the grains as spherical Gray [10] proposes a model to calculate the terminal settling velocity:

$v_{s l}=\sqrt{\frac{4 g D_{s}\left(\rho_{s}-\rho_{g}\right)}{3 \rho_{g} C_{D}} \frac{\Psi}{1+D_{s} / D_{H}}}$

Here, $v_{s l}$ : terminal settling velocity; $D_{s}$ : Equivalent diameter of the grain; $\rho_{s}$ :grain density; $\rho_{g}$ :gas density; $C_{D}$ :friction coefficient; $\Psi$ :sphericity, dimensionless; $D_{H}$ :the hydraulic diameter of the flow tunnel.

The required gas velocity to carry the solid grains:

$v_{g}=v_{s l}+v_{t r}$

$v_{t r}=\frac{\pi d_{b}^{2}}{4 C_{p} A}\left(\frac{R_{p}}{3600}\right)$

Here $v_{g}$ : gas flow velocity; $v_{t r}$ : the velocity of the cutting motion; $d_{b}$ : the diameter of the drill bit. $R_{p}$ : the rate of penetration; $C_{p}$ : the volumetric fraction of the grain in the tunnel.

Using Gray's model, Bradshaw concludes that when the solid volumetric fraction is larger than 0.04 the grains start to settle in the air and the interaction between their particles starts to enhance. So the errors still exist in the calculation results because the flow is treated as single phase flow even though the volumetric fraction of solid is larger than 0.04 .

\subsection{The Key Point Method Considering the Motion of Single Particle}

The aim behind the calculation of the minimum gas injection rate is to guarantee the efficiency of carrying the cuttings in the annulus. According to gas compressibility and the setting of the drill strings, the intersection between the upper part of the drill collar and the drill string is called the main point since the flow velocity is minimum at this point, being prone to bring about cutting and carrying problem [11$18]$.

The viscous friction on the cuttings:

$F_{d}=C_{d} \cdot \frac{1}{2} \rho_{g}\left(V_{g}-V_{s}\right)^{2} \cdot \frac{1}{4} \pi d_{s}^{2}$

$C_{d}=f(\mathrm{Re})$

$\operatorname{Re}=\frac{\rho_{g} d_{s}\left|V_{g}-V_{s}\right|}{\mu}$

Here, $F_{d}$ is the viscous friction on the cuttings; $\rho_{g}$ is the density of gas; $V_{g}, V_{s}$ are the gas and cutting lifting velocity, respectively; $d_{s}$ is the diameter of the cutting; $\mu$ is gas viscosity.

Suppose the domain forces acting on the spherical particles are: gravity $F_{w}$, buoyancy $F_{t}$ and viscous friction $F_{d}$, the condition which makes the cutting particle lifting is as:

$F_{t}+F_{d} \geq F_{w}$

Then the minimum injection rate to carry cutting efficiently can be calculated.

\subsection{Discussion on the Minimum Gas Injection Rate Calculation Models}

Angel Model is the most classic Minimum Kinetic Energy Standard Model that was commonly being used till the end of last century. The problem is that its calculated value is $20-30 \%$ lesser than the practical required value. Boyun Guo introduced the Nikuradse friction coefficient into Angel Model to minimize this difference between their values.

The Minimum Velocity Standard Model is the most commonly used method. But the calculated gas rate is quite discouraging [19]. The reason behind this lacking is that the supposed spherical particle is far from the industry practice. The effect of the grain shape to the flow resistance cannot be ignored. . The resistance coefficient of objectives with different shapes may vary to a great extent. So the practical application of this method is limited by the course estimation of unknown parameters such as grain shape and size.

In the late 20th century, a lot of scholars tried to apply the key point method considering the motion of single particle. Although this method is theoretically convenient still it fails to consider the interaction between the flowing particles, such as windward effect and shielding effect. The calculation result deviated from the practice was usually less than the optimum rate. In addition, the accuracy of this method also depends on the drill bits, formation and rate of penetration. A correlation factor $\mathrm{K}$, with values ranging from 1.2-1.3, is recommended to be applied into this method.

The minimum gas injection rate calculated by these three methods is all under the international standard atmosphere condition, which is $0.101325 \mathrm{MPa}, 15{ }^{\circ} \mathrm{C}$. However, in the high-altitudes areas, such as the western zone in China, where the air compressor is placed the local atmosphere pressure and air humidity where the air compressor is found to be different compared with the standard condition. So the conventional minimum gas injection rate models are considered unsuitable for the high altitudes areas. Elevation correlations should be based on the conventional models.

\section{THE INFLUENCE OF ELEVATION AND AIR HU- MIDITY TO THE MINIMUM GAS INJECTION RATE CALCULATION}

The local air density changes with the elevation, influencing the calculation of the minimum gas injection rate. Besides the local air density, the air humidity also varies as the elevation difference. Moreover, the air humidity not only influences the density of the borehole fluid but also the flow regime, which also affects the calculation of the minimum gas injection rate. Consequently, if the air flow 
meter is not calibrated by the local atmosphere pressure, some correlation is needed to be applied. But if the flow meter is calibrated, the reading is found to be correct, not requiring any correlation.

\subsection{The Influence of the Elevation to the Minimum Gas Injection Rate}

The actual atmosphere density decreases exponentially as the elevation increases. The expression is [20]:

$$
\rho_{z}=\rho_{o} \cdot e^{-\frac{z}{z_{o}}}
$$

Here, $\mathrm{Z}$ is elevation, $\mathrm{m}$; $\rho_{z}$ is the air density at a certain elevation $\mathrm{Z}, \mathrm{kg} / \mathrm{m} 3 ; \rho_{o}$ is the air density under standard atmosphere pressure, $\mathrm{kg} / \mathrm{m} 3 ; \mathrm{Zo}$ is the height of homogeneous air, $\mathrm{m}$.

Therefore, according to the mass conservation theory, for the calculation of the minimum gas injection rate in the air underbalanced drilling, the elevation density decreases correlation factor is as: $f_{\rho}=e^{\frac{z}{z_{0}}}$. And the minimum gas injection rate after the correlation is:

$$
Q_{\min }=f_{\rho} \cdot Q_{\min 0}=Q_{\min 0} \cdot e^{\frac{z}{z_{0}}}
$$

Here, $Q_{\min }$ is the minimum gas injection rate at local condition; $Q_{\min 0}$ is the gas injection rate at standard condition.

Fig. (1). shows how the curve of $f_{\rho}$ changes with elevation. $f_{\rho}$ increases rapidly with the increase in the elevation. For the oil fields in the western China, such as Qinghai, Yumen and Tarim, $f_{\rho}$ is relatively higher. For instance, $f_{\rho}$ in Qinghai Oil Field can be 1.46 with altitudes of $3000 \mathrm{~m}$, reporting the local minimum gas injection rate as 1.46 times larger than the theoretical value.

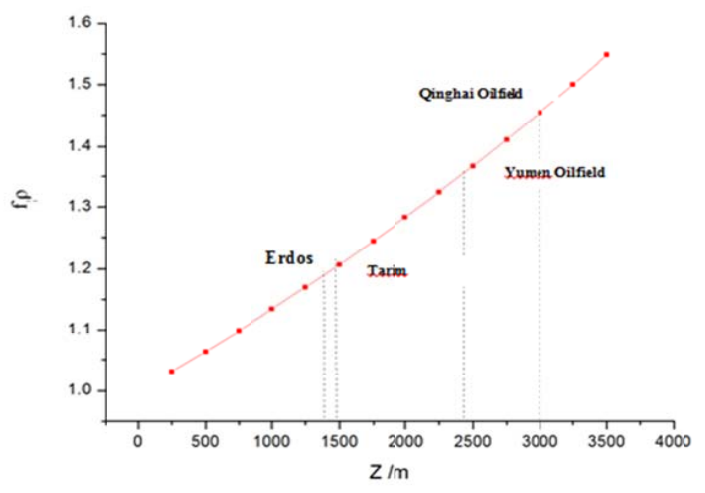

Fig. (1). How $f_{\rho}$ Changes with Elevation.

\subsection{The Influence of the Air Humidity to the Minimum Gas Injection Rate}

Air used in air drilling is dehumidified before entering the compressor. Since most of the moisture in the air gets removed in the dehumidification process, the amount of injected air becomes larger than the air that actually enters the well bore. The correlation factor of air humidity is $f_{e}$.

According to the Dalton's partial pressure law, the total pressure of a gas mixture equals to the partial pressure of all the components. So the total pressure of the wet air $(p)$ should be equal to the partial pressure of the dry air $\left(p_{d}\right)$ and the partial pressure of the moisture $\left(p_{e}\right)$ [21], which is: $p=p_{d}+p_{e}$.

If the dehumidification efficiency is $y_{e}$, the residual air after dehumidification $\left(\varepsilon_{d}\right)$ is:

$\varepsilon_{d}=\frac{p_{d}}{p_{d}+p_{e}}=\frac{p-y_{e} \cdot p_{e}}{p}$

Furthermore, according to the air relative humidity:

$p_{e}=x_{e} \cdot p_{w}$

Here, $x_{e}$ is the air relative humidity, $\% ; p_{w}$ is the air saturation vapor pressure at the certain temperature, $\mathrm{Pa}$.

$p_{w}$ can be expressed by Magnus's semi-empirical formula [22]:

$p_{w}=p_{w 0} \cdot 10^{\frac{a t}{b+t}}$

Here, $p_{w 0}$ is the saturation vapor pressure at $0^{\circ} \mathrm{C}$, which is $611 \mathrm{~Pa}$; $\mathrm{t}$ is Evaporation surface temperature; $\mathrm{a}, \mathrm{b}$ are two empirical coefficients, at horizontal surface: $a=7.45, \quad b=237.3$.

The expression of the residual air after the humidification is:

$\varepsilon_{d}=\frac{p-y_{e} \cdot x_{e} \cdot p_{w 0} \cdot 10^{\frac{a t}{b+t}}}{p}$

The correlation factor of air humidity $f_{e}$ is:

$f_{e}=\frac{1}{\varepsilon_{d}}=\frac{p}{p-y_{e} \cdot x_{e} \cdot p_{w 0} \cdot 10^{\frac{a t}{b+t}}}$

Fig. (2) shows how $f_{e}$ changes with temperature under different relative humidity. Obviously, $f_{e}$ is influenced by temperature and humidity. $f_{e}$ tends to increase as the temperature and humidity increase.

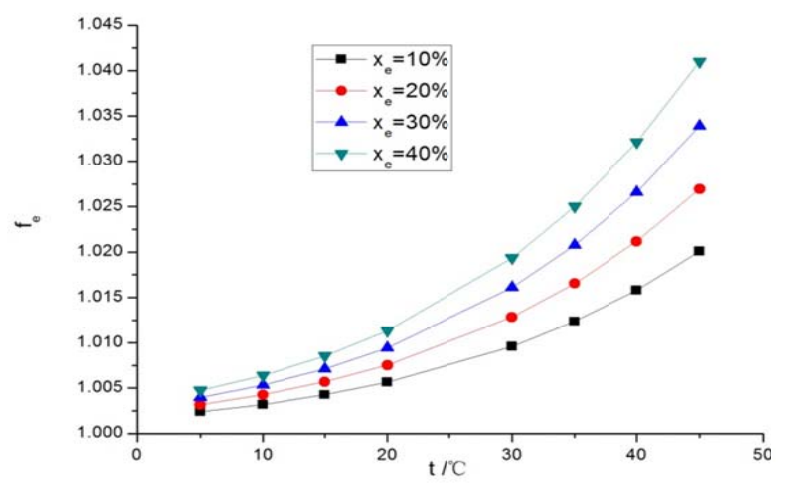

Fig. (2). Curves of $f_{e}$ changes with temperature under different relative humidity. 
Table 1. Well Data

\begin{tabular}{|l|l|l|l|}
\hline Well Depth & $\mathbf{1 5 0 7 . 4} \mathbf{~ m}$ & Drill Collar & $\mathbf{6 - 1 / 2 "}$ \\
\hline \hline Casing & $9-5 / 8^{\prime \prime}$ & Drill String & $5^{\prime \prime}+5^{\prime \prime}($ Heavy) \\
\hline Bit Size & $8-1 / 2^{\prime \prime}$ & Rate of Penetration & $9.6 \mathrm{~m} / \mathrm{h}$ \\
\hline Ground Temperature & $-5^{\circ} \mathrm{C}$ & Geothermal Gradient & $2.7^{\circ} \mathrm{C} / 100 \mathrm{~m}$ \\
\hline Lithology & Mud stone & Cutting Diameter & $4 \mathrm{~mm}$ \\
\hline Elevation & $1455 \mathrm{~m}$ & Air Relative Humidity & $30.50 \%$ \\
\hline
\end{tabular}

Table 2. Comparison of the Calculation Result

\begin{tabular}{|c|c|c|c|c|c|}
\hline & \multicolumn{2}{|c|}{$\begin{array}{c}\text { Minimum Kinetic Energy } \\
\text { Standard }\end{array}$} & $\begin{array}{c}\text { Minimum Velocity } \\
\text { Standard }\end{array}$ & $\begin{array}{c}\text { Key Point Method considering the } \\
\text { motion of single particle }\end{array}$ & $\begin{array}{c}\text { Actual gas } \\
\text { injection rate }\end{array}$ \\
\hline \hline \multirow{2}{*}{$\begin{array}{c}\text { Without elevation and } \\
\text { humidity correlation }\end{array}$} & $\begin{array}{c}\text { Angel } \\
\text { Equation }\end{array}$ & $\begin{array}{c}\text { Boyun Guo } \\
\text { Correlation }\end{array}$ & & 63.4 & 76.7 \\
\cline { 2 - 6 } & 56.4 & 71.6 & 54.9 & 65 \\
\hline $\begin{array}{c}\text { With elevation and } \\
\text { humidity correlation }\end{array}$ & 68.2 & 86.6 & 66.4 & 75 \\
\hline
\end{tabular}

Note: dry air pressure is $1013.25 \mathrm{~Pa}$ and $y_{e}$ is 0.96 .

Consider the influence of both elevation and air humidity to the minimum gas injection rate, the minimum gas injection rate under local condition is:

$Q_{\min }=f_{a} \cdot Q_{\min 0}$

$f_{a}$ is a comprehensive correlation factor.

And,

$$
f_{a}=f_{e} \cdot f_{\rho}
$$

Equation (14) and (15) are the equations of gas injection rate after correlation of elevation and the air humidity.

\section{CASE ANALYSIS}

Take one real air drilling project as an example. All of the three models are used to calculate the minimum gas injection rate. The elevation and air humidity correlations are applied. The well data is shown in Table 1.

The minimum gas injection rate calculation result has been shown in Table 2. The spherical degree in Minimum Velocity Standard Model is supposed to be 1, and the grain shape factor is supposed to be 0.85 .

The above table highlights existence of large differences among the minimum gas injection rate calculated by different models. The elevation and humidity correlation also influence the result. And this difference becomes larger as the elevation and humidity increase. This example shows that the calculation result of Minimum Kinetic Energy Standard Model using Boyun Guo's correlation and calibrated by elevation and humidity correlation is closest to the practice while the other methods have relative larger errors.

\section{CONCLUSIONS}

This paper discusses the calculation of minimum gas injection rate considering the aspects of model selection, the influence of elevation and the air humidity Along with the correlation factor of the elevation and air humidity. It is concluded that both elevation and the air humidity influence the minimum gas injection rate under local condition:

- As the elevation increases, the elevation correlation factor increases. The air drilling project in high altitudes zones, such as western China, requires more attention to the effect of the rig elevation. The correlation factor in Qinghai can be as high as 1.5.

- As the air humidity increases, the humidity correlation factor increases. As before raining in summer, both the air humidity and the temperature are high. At this time the humidity correlation factor can be as high as 1.1 .

- Analyzing the calculation example, the result of Minimum Kinetic Energy Standard model using Boyun Guo correlation and calibrated by elevation and humidity correlation is the closest to the and could be used in industry. The other models have relative larger errors.

\section{CONFLICT OF INTEREST}

The authors confirm that this article content has no conflicts of interest.

\section{ACKNOWLEDGEMENTS}

This work is supported by the National Natural Science Foundation of China (No.51034007 and No.51104172), the National Science and Technology Major Project of China(No).2011ZX05026-001) , "PCSIRT" Project No. 
IRT1086, the Natural Science Foundation of Shandong Provence of China（No.ZR2010EL101.

\section{REFERENCES}

[1] Y.C. Zhou, and H.J. Zhai, The Application of Underbalanced Drilling Technique, Petroleum Industry Press: Beijing, 2003.

[2] L.T. Wang, Q.D. Sun, and L.D. Zhang, New Drilling Technology Progress, China Petrochemical Press: Beijing, 2001.

[3] W. Wei, H. Le, and Q.C. Xu, Applied Air Drilling Technology, The University of Petroleum of China Press: Dongying, 2008.

[4] H.W. Jiang., S.B. Xing, and K.X. Wang, "Research on the relation of air volume flow rate and formation water production in air drilling", Petroleum Geology \& Oilfield Development in DaQing, vol. 27, no. 2, pp. 106-109, 2008.

[5] Z.J. Jiang, "Research on the mechanism for carrying debris and water about gas drilling on condition of formation water output", Drilling \& Production Technology, vol. 31, no. 1, pp. 12-14, 2008.

[6] W. C. Lyons, B.Y. Guo, and F. A. Seidel, Air and Gas Drilling Manual, McGraw-Hill: NY, 2001.

[7] R.R. Angel, Volume Requirements for Air or Gas Drilling, Gulf Publishing Company: Houston, pp. 29-64, 1958.

[8] B.Y. Guo, and A. Ghalambor, Gas Volume Requirements for Underbalanced Drilling, PennWell Books: Tulsa, US, 2008.

[9] C.X. Wang, Y.F. Meng, and D. Hu, "Study advances in gas volume requirement calculation for gas drilling", Natural Gas Industry, vol. 26, no.12, pp. 97-99, 2006.

[10] K.E. Gray, The cutting carrying capacity of air at pressure above atmospheric, Transactions on AIME, vol. 2010, pp. 325-330, 1957.

[11] Y.R. Zhao, Y.f., Meng, and T. Lei, Theory and Practice of Air Drilling, Petroleum Industry Press: Beijing, pp.25-28, 2007.
[12] N.B. Wood, "A simple method for the calculation of turbulent deposition to smooth and rough surfaces", Journal of Aerosol Science, vol. 12, pp. 275-290, 1981.

[13] W.C. Hinds, Aerosol Technology: Properties, Behavior, and Measurement of Airborne Particles. Wiley: New York 1984.

[14] Y. Wang, and P.W. James, "On the effect of anisotropy on the turbulent dispersion and deposition of small particles", International Journal of Multiphase Flow, vol. 25, pp. 551-558, 1999.

[15] H. Zhang, and G. Ahmadi, "Aerosol particle transport and deposition in vertical and horizontal turbulent duct flows", Journal of Fluid Mechanics, vol. 406, pp. 55-80, 2000.

[16] A.C.K. Lai, and W.W. Nazaroff, "Modeling indoor particle deposition from turbulent flow onto smooth surfaces", Journal of Aerosol Science, vol. 31, pp. 463-476, 2000.

[17] B. Oesterle, L.I. Zaichik, "On Lagrangian time scales and particle dispersion modeling in equilibrium turbulent shear flows", Physics of Fluids, vol. 16, pp. 3374-3384, 2004.

[18] L. Tian, and G. Ahmadi, "Particle deposition in turbulent duct flows-comparisons of different model predictions", Journal of Aerosol Science, vol. 38, pp. 377-397, 2007.

[19] C.Y. Han, G. Long, and H.P. Ji, "Dynamics analysis of cutting on gas drilling", Chongqing Institute Of Science And Technology Journal(Natural Science), vol. 10, no.6, pp. 31-39, 2008.

[20] Z.S. Zhou, Meteorology and Climatology (3rd Verson), Higher Education Press: Beijing, 1997.

[21] J. Liu, and X.J. Xu, Meteorology, China Agriculture Press: Beijing, 2002.

[22] Z.Q. Hua, and Z.J. Zhang, Engineering Thermodynamics, Higher Education Press: Beijing, 2000.

(C) Sun et al.; Licensee Bentham Open.

This is an open access article licensed under the terms of the Creative Commons Attribution Non-Commercial License (http://creativecommons.org/licenses/by-nc/3.0/) which permits unrestricted, non-commercial use, distribution and reproduction in any medium, provided the work is properly cited. 